\title{
CONTACT BETWEEN HAMSTER SPERMATOZOA AND THE ZONA PELLUCIDA RELEASES A FACTOR WHICH INFLUENCES EARLY BINDING STAGES
}

\author{
J. F. HARTMANN AND C. F. HUTCHISON \\ Merck Institute for Therapeutic Research, Rahway, New Fersey, U.S.A.
}

(Received 16th April 1973)

\begin{abstract}
Summary. The studies reported here demonstrate that isolated hamster zonae pellucidae affect the binding between capacitated hamster spermatozoa and eggs included in the same drop. Mouse zonae pellucidae fail to affect binding between hamster gametes. These results suggest that binding, which occurs only between homologous spermatozoa and isolated zonae pellucidae causes a factor ( $\mathrm{S} 1$ factor) to be released. The $\mathrm{S} 1$ factor is diffusible and influences the two successive binding steps (B1 and B2) previously shown to occur between capacitated spermatozoa and eggs. The B2 step is delayed by the action of the S1 factor during the early part of the interval between $\mathrm{B} 1$ and $\mathrm{B} 2$ suggesting that the effect may be mediated through B1. It is proposed that the S1 factor is also released during the first binding interaction (B1) between the spermatozoa and the egg which appears to be an analogous but terminated form of the binding to the isolated zona pellucida. The data are consistent with the possibility that the Bl step is terminated by the product of the interaction between the $\mathrm{S} 1$ factor and a factor from the vitellus or perivitelline space.
\end{abstract}

\section{INTRODUCTION}

Most studies of fertilization have been concerned with the penetration process (Srivastava, Adams \& Hartree, 1965; Stambaugh \& Buckley, 1968) and those steps which follow (Barros \& Yanagimachi, 1971; Gwatkin, Williams, Hartmann \& Kniazuk, 1973). We have been studying the pre-penetration reactions between the surfaces of hamster gametes in vitro and found them to be complex (Hartmann, Gwatkin \& Hutchison, 1972; Hartmann \& Hutchison, 1974). First, hamster spermatozoa attach loosely and species-non-specifically to the surface of the zona pellucida. Approximately 2 min later, the spermatozoa begin to bind tightly. This binding, which is species-specific and designated B1, is terminated after 1 to $2 \mathrm{~min}$. Termination involves a factor from the vitellus or perivitelline space which acts directly or indirectly on the spermatozoa. Experiments with p-aminobenzamidine, a trypsin inhibitor, suggest that a protease, which is either the vitelline factor or a sperm protease dependent upon it, terminates first binding. Following termination, the spermatozoa remain 
attached and approximately 30 min later begin to bind a second time by a different sperm site. This second binding stage (B2) is dependent upon the vitelline factor. Step B2 is completed $35 \mathrm{~min}$ after B1 and penetration of the zona pellucida by the spermatozoon begins.

To gain more information about the nature of $\mathrm{B} 1$ we have studied sperm binding to the isolated zona pellucida, which appears to be an analogous but unterminated form of $\mathrm{B} 1$. Our results suggest that a diffusible factor is released into the medium during the interaction between the isolated zona pellucida and spermatozoa. The factor markedly affects the early binding interactions between the spermatozoa and the egg.

\section{MATERIALS AND METHODS}

Spermatozoa were collected from the epididymis of the golden hamster, Mesocricetus auratus, and capacitated by the method described by Gwatkin \& Williams (1970). Spermatozoa were capacitated by adding $20 \mu \mathrm{l}$ sperm suspension $\left(2 \times 10^{7}\right.$ spermatozoa $\left./ \mathrm{ml}\right)$ under mineral oil to equal volumes of medium containing the content of an oviduct ( $17 \mathrm{hr}$ after injection of HGG). After incubation at $37^{\circ} \mathrm{C}$ for $5 \mathrm{hr}$, ova which had been introduced with the oviduct content were removed, the drops were pooled, fresh $40-\mu \mathrm{l}$ drops were prepared under oil and other hamster or mouse eggs ( 20 to $22 \mathrm{hr}$ after injection of HCG), free of cumulus, were added to each drop. Cumulus was removed with hyaluronidase (450 units/ml in Dulbecco's phosphate-buffered saline containing $1 \%$ polyvinyl pyrrolidone). Hamster and mouse zonae pellucidae were isolated without damage to the vitellus, by forcing eggs through a micropipette with an inner diameter of $50 \mu \mathrm{m}$. The zonae pellucidae were washed by passing them through three changes of 199M2. Binding was scored after washing eggs or zonae pellucidae with three changes of 199M2 as previously described (Hartmann \& Gwatkin, 1971).

In this paper, the term zona pellucida refers to the isolated structure and the term egg refers to the zona pellucida plus vitellus.

To determine whether a diffusible factor was being released, hamster spermatozoa and zonae pellucidae were incubated together and the latter with any associated spermatozoa were removed with a micropipette 10 min later. Eggs were then added to the drop. Binding to eggs was scored after 3 and 40 min to test for $\mathrm{B} 1$ and $\mathrm{B} 2$, respectively.

To determine if the inhibition was exerted early or late in the period preceding B2, the following experiment was carried out. In one set of drops, eggs, zonae pellucidae and spermatozoa were incubated for $20 \mathrm{~min}$ and the zonae pellucidae with any bound spermatozoa were then removed. In a parallel series, the zonae pellucidae were added after the spermatozoa and eggs were together for $20 \mathrm{~min}$. Binding was recorded $40 \mathrm{~min}$ after mixing of spermatozoa and eggs.

\section{RESULTS}

Table 1 shows that when eggs and zonae pellucidae were placed together in the same drop, binding (B2) of spermatozoa to the eggs was depressed. Inhibition of binding to eggs did not occur when mouse zonae pellucidae, to which 
hamster spermatozoa attach but do not bind, were substituted for their hamster counterparts. Media which had held zonae pellucidae also failed to affect binding when added simultaneously with eggs to spermatozoa.

In the course of forty experiments, inhibition of binding to eggs in the presence of hamster zonae pellucidae was consistently observed. This was in sharp contrast to the binding of spermatozoa to the zonae pellucidae in these drops, which was partly inhibited in only $20 \%$ of these experiments.

Table 1. Hamster spermatozoa binding to eggs in drops containing both eggs and isolated zonae pellucidae

\begin{tabular}{l|c|c}
\hline \multicolumn{1}{c|}{ Drop contents } & $\begin{array}{c}\text { Total no. of sperm. } \\
\text { bound to eggs }\end{array}$ & $\begin{array}{c}\% \text { of } \\
\text { eggs with } \\
\text { bound sperm. }\end{array}$ \\
\hline Hamster eggs & $>100$ & 100 \\
Hamster eggs+ hamster zonae & $9 \pm 4$ & 27 \\
Hamster eggs + mouse zonae & $>100$ & 100 \\
\hline
\end{tabular}

Fifteen zonae pellucidae and/or fifteen eggs were added to $40-\mu \mathrm{l}$ drops of capacitated spermatozoa and binding was scored $40 \mathrm{~min}$ later. Each value in the mixed drop experiment represents the mean \pm standard deviation of three experiments.

Table 2. Production of a diffusible factor which affects steps B1 and B2 in the binding of capacitated spermatozoa to eggs

\begin{tabular}{r|c|c|c}
\hline \multirow{2}{*}{$\begin{array}{c}\text { Time } \\
(\text { min })\end{array}$} & \multicolumn{3}{|c}{ Total number of sperm. bound to eggs } \\
\cline { 2 - 4 } & $\begin{array}{c}\text { Without zonae } \\
\text { pellucidae }\end{array}$ & $\begin{array}{c}\text { After removal of } \\
\text { hamster zonae pellucidae }\end{array}$ & $\begin{array}{c}\text { After removal of } \\
\text { mouse zonae pellucidae }\end{array}$ \\
\hline 3 & $30 \pm 0$ & 0 & $3 \pm 0$ \\
40 & $70 \pm 20$ & $10 \pm 8$ & $75 \pm 22$ \\
\hline
\end{tabular}

Spermatozoa and fifteen zonae pellucidae were mixed in $40-\mu 1$ drops. The zonae pellucidae and bound spermatozoa were removed $10 \mathrm{~min}$ later and were replaced with ten eggs. The binding of the remaining spermatozoa to eggs was scored at the indicated times. Each value is the mean of four experiments \pm standard deviation.

The results in Table 2 show that B1 $(3 \mathrm{~min})$ and $\mathrm{B} 2(40 \mathrm{~min})$ were affected in those drops which had contained hamster but not mouse zonae pellucidae. (The presumed factor which affects the binding of the spermatozoa to the egg and is released into the medium is referred to in this paper as the $\mathrm{S} 1$ factor.)

Experiments were conducted to determine how long B2 is inhibited by the S1 factor. Text-figure 1 shows the results of experiments in which spermatozoa, eggs and zonae pellucidae were combined for various periods. It can be seen that B1 was not evident and that B2 was delayed. Inhibition of B2 at $50 \mathrm{~min}$ was reproducible, but binding was variable at $60 \mathrm{~min}$. By $90 \mathrm{~min}$, the incidence of sperm penetration of eggs in the presence or absence of zonae pellucidae was equal. 


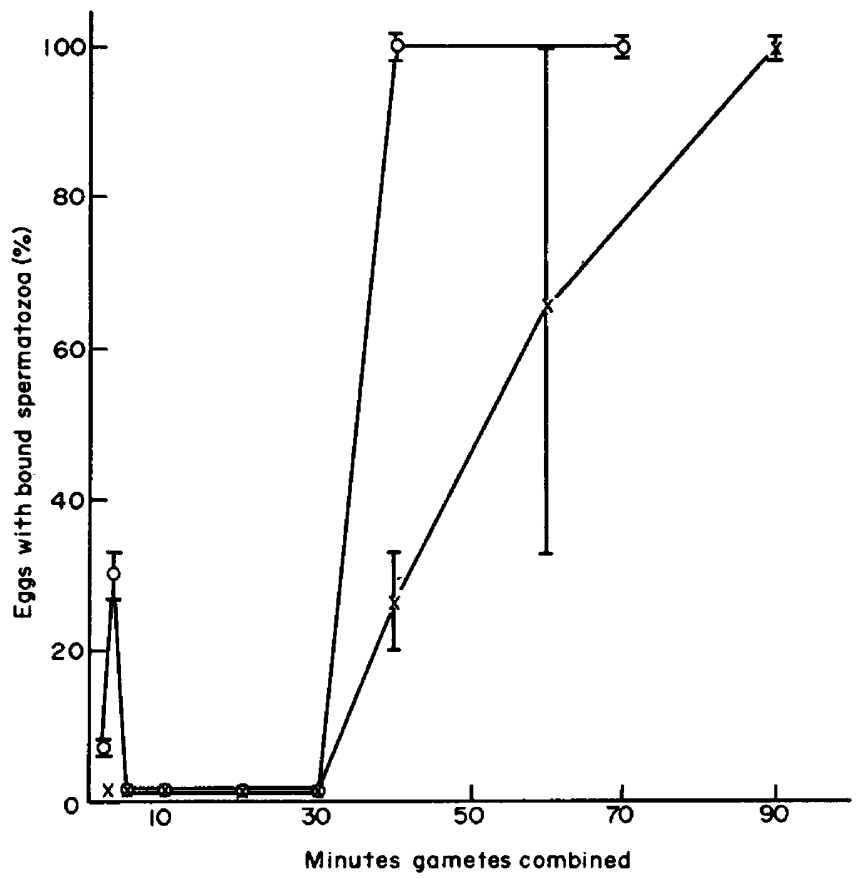

TEXT-FIG. 1. Sperm binding to fifteen eggs in presence $(x)$ and absence $(O)$ of fifteen hamster zonae pellucidae. Each point is the mean of two experiments with the range.

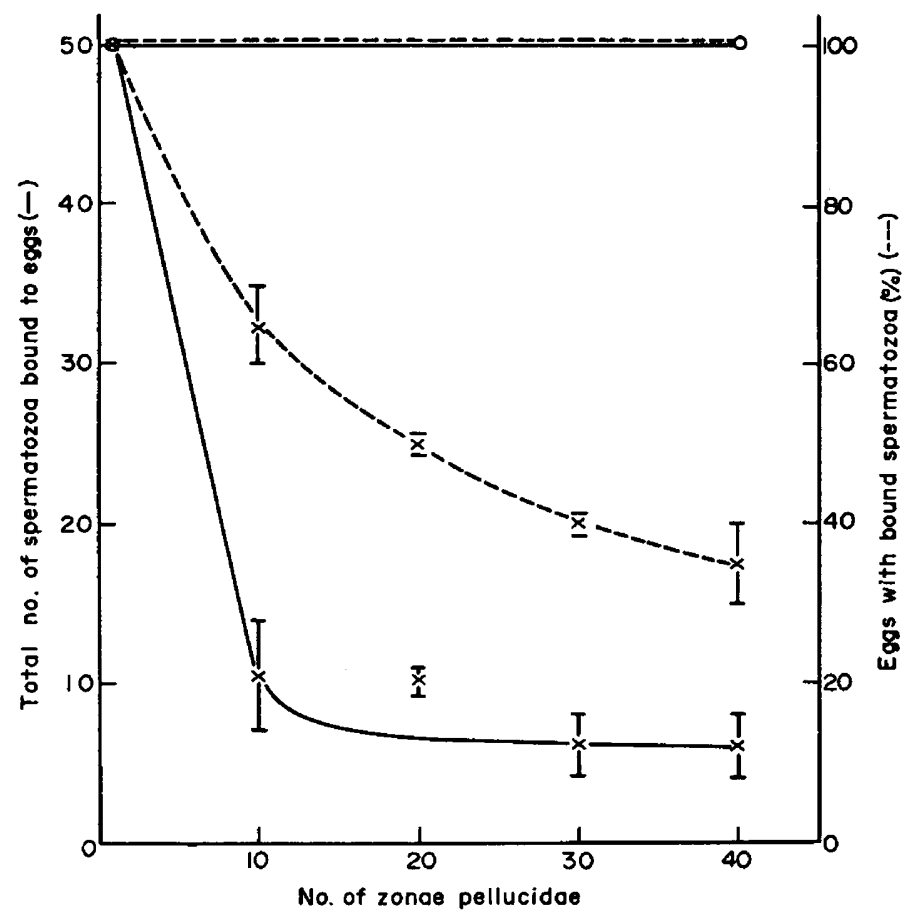

TEXT-FIG. 2. Sperm binding to eggs after $\mathbf{4 0} \mathrm{min}$ in the presence of increasing numbers of zonae pellucidae. Each point represents the mean of two experiments with the range. $x$, Hamster zonae pellucidae; $O$, mouse zonae pellucidae. Ten eggs were used in each drop. 
The S1 factor was titrated using a series of drops, each containing spermatozoa, ten eggs and one to forty zonae pellucidae (Text-fig. 2). The effect of varying numbers of zonae pellucidae on the binding of spermatozoa caused a sharp decline in the total number of spermatozoa bound to the eggs. With greater numbers of zonae pellucidae, the inhibition did not increase much or at all. Four to eight spermatozoa remained bound to the eggs in the presence of forty zonae pellucidae, with never more than two spermatozoa bound to an egg. An equal number of mouse zonae pellucidae had no effect on binding.

Table 3. Inhibition of step $\mathrm{B} 2$ in the binding of capacitated spermatozoa to eggs as a function of the period in which zonae pellucidae are present

\begin{tabular}{c|c|c|c}
\hline $\begin{array}{c}\text { Period when } \\
\text { zonae pellucidae } \\
\text { are present } \\
\text { (min before B2) }\end{array}$ & $\begin{array}{c}\text { Species } \\
\text { of zonae } \\
\text { pellucidae }\end{array}$ & $\begin{array}{c}\text { Total no. of } \\
\text { sperm. bound }\end{array}$ & $\begin{array}{c}\% \text { of } \\
\text { eggs with } \\
\text { bound sperm. }\end{array}$ \\
\hline 1 to 20 & Hamster & $18 \pm 2$ & 60 \\
20 to 40 & Hamster & $90 \pm 5$ & 100 \\
1 to 20 & Mouse & $95 \pm 10$ & 100 \\
20 to 40 & Mouse & $95 \pm 10$ & 100 \\
- & No zonae & $100 \pm 10$ & 100 \\
\hline
\end{tabular}

Fifteen eggs and fifteen isolated zonae pellucidae were used in each experiment. Binding was scored 40 min after mixing. Each value represents the mean of two separate experiments with ranges.

The data (Table 3) show that the presence of zonae pellucidae up to $20 \mathrm{~min}$, but not thereafter, inhibited binding to eggs. In separate drops, the inclusion of mouse zonae pellucidae and their removal with attached spermatozoa after $20 \mathrm{~min}$ had no effect on sperm binding.

\section{DISCUSSION}

The results presented in this report suggest that during the association between capacitated hamster spermatozoa and zonae pellucidae, a factor is released which affects the early binding reactions between egg and spermatozoa. The failure of mouse zonae pellucidae to produce any noticeable effect suggests, but does not prove, that the $\mathrm{S} 1$ factor is a product of the binding reaction.

The use of mouse zona pellucidae provides an important control in another regard. Since hamster spermatozoa only attach to heterologous zonae pellucidae (J. F. Hartmann and C. F. Hutchison, unpublished observations), the effects observed in the isologous experiments cannot be due to the removal by attachment to the zonae pellucidae of a portion of the sperm population which is capable of binding.

The effect on the second binding by the SI factor is exerted during the early period preceding B2 suggesting that the delay may be mediated through an effect on B1. Thus, a relationship between the two bindings appears possible. Comparative studies suggest that binding to the zona pellucida is an analogous but unterminated form of $\mathrm{B} 1$. We base this conclusion on the observation that 
both phenomena are specific, trypsin sensitive (Hartmann \& Gwatkin, 1971; Hartmann \& Hutchison, 1974; J. F. Hartmann and C. F. Hutchison, unpublished observations) and occur at the same time (Hartmann \& Hutchison, 1974). It is possible, therefore, that the $\mathrm{S} I$ factor is also released during the first binding between gametes and may play a rôle in the termination of that binding. The effects we observe of the SI factor generated by spermatozoa-zona pellucida binding can be interpreted as the consequence of the action of an excess exogenous quantity of the factor which delays $\mathrm{B} 2$ by inhibiting the $\mathrm{Bl}$ reactions.

We propose the hypothesis that the vitelline factor, previously shown to affect spermatozoa-egg binding interactions (Hartmann et al., 1972), must interact with the $\mathrm{S} 1$ factor in order to terminate $\mathrm{B}$. The product of this interaction, therefore, can only originate from binding between gametes. By contrast, spermatozoa-zona pellucida-generated S1 factor would not interact with the vitelline factor until it reached the egg-sperm interface where the vitelline factor is present. The assumption that the active product is unstable explains its inability consistently to terminate zona pellucida-spermatozoa binding which occurs at a distance from the normal site of action.

Earlier results with an inhibitor suggest that termination of first binding involves a protease (Hartmann \& Hutchison, 1974), and some proteases are notoriously unstable (Schroeder \& Shaw, 1968). Thus, S1 or the vitelline factor may be a protease.

In a previous study, we presented evidence that the vitelline factor conditioned the spermatozoa in a manner which affected its ability to bind (Hartmann et al., 1972). Interpreted in terms of more recent findings (Hartmann \& Hutchison, 1974), it was suggested that the vitelline factor is involved in Bl termination and conditioning of the spermatozoa to bind through the B2 site. We propose above that the vitelline factor interacts with the S1 factor and therefore acts indirectly to terminate B1. Similarly, the B2 site may be conditioned by an activated S1 factor, or the vitelline factor may condition the spermatozoa directly. A distinction between these possibilities cannot yet be made.

\section{REFERENGES}

Barros, C. \& Yanagimachi, R. (1971) Induction of zona reaction in golden hamster eggs by cortical granule material. Nature, Lond. 233, 268.

Gwatkin, R. B. L. \& Williams, D. T. (1970) Inhibition of sperm capacitation in vitro by contraceptive steroids. Nature, Lond. 227, 182.

Gwatkin, R. B. L., Williams, D. T., Hartmann, J. F. \& Kniazuk, M. L. (1973) The zona reaction of hamster and mouse eggs: production in vitro by a trypsin-like protease from cortical granules. J. Reprod. Fert. 32, 259.

Hartmann, J. F. \& Gwatkin, R. B. L. (1971) Alteration of sites on the mammalian sperm surface following capacitation. Nature, Lond. 234, 479.

Hartmann, J. F., Gwatkin, R. B. L. \& Hutchison, C. F. (1972) Early contact interactions between mammalian gametes in vitro: evidence that the vitellus influences adherence between sperm and zona pellucida. Proc. natn. Acad. Sci. U.S.A. 69, 2767.

Hartmann, J. F. \& Hutchison, G. F. (1974) Nature of the pre-penetration contact interactions between gametes of the golden hamster in vitro. F. Reprod. Fert. 36, 49.

Schroeder, D. D. \& SHAw, E. (1968) Chromatography of trypsin and its derivatives: characterization of a new active form of bovine trypsin. 7. biol. Chem. 243, 2943.

Srivastava, P. N., Adams, C. E. \& HartreE, E. F. (1965) Enzymic action of acrosomal preparations on the rabbit ovum in vitro. F. Reprod. Fert. 10,61.

Stambaugh, R. \& Buckley, J. (1968) Zona pellucida dissolution enzymes of the rabbit sperm head. Science, N.Y. 161, 585. 